\title{
Cochlear Implant Practice Patterns: The U.S. Trends with Pediatric Patients
}

DOI: $10.3766 /$ jaaa.17011

\author{
Carly Hemmingson* \\ Jessica J. Messersmith*
}

\begin{abstract}
Background: Many factors affect an individual's outcomes with a cochlear implant (Cl); however, quality of device programming and consistency of follow-up appointments have been shown to be crucial contributors. As audiologists' $\mathrm{Cl}$ caseloads increase, time constraints on appointments also increase, thus fueling the need for efficient and effective programming strategies. Currently, there are no standardized guidelines describing what methods should be used during programming, nor are there standardized schedules that delineate what procedures should be performed at specific appointment intervals. Without standardized programming guidelines, clinical practices may be variable and may not align with best practice research; thus, outcomes with a $\mathrm{Cl}$, particularly for pediatrics, may not be reflective of the actual potential available.

Purpose: The purpose of this study was to identify the clinical practice patterns used by U.S. audiologists when programming and providing follow-up care to children who use Cls. This study aimed to determine the following: common programming approaches, provision intervals for these procedures, common validation assessments, typical follow-up care schedules, and source(s) of $\mathrm{Cl}$ training. In addition, this study sought to evaluate if training and/or follow-up care differed between small and large $\mathrm{Cl}$ centers.
\end{abstract}

Research Design: A cross-sectional survey design was used.

Study Sample: Target population included practicing audiologists working with pediatric $\mathrm{Cl}$ users throughout the United States. Participation was voluntary, thus random selection could not be used. A total of 167 participants opened and began the online survey and 113 successfully completed the survey instrument (23.99\% return rate).

Data Collection and Analysis: Potential participants were identified using the "find a clinic" function on three Cl manufacturers' websites. Potential participants were asked to complete an online survey seeking information about practices they employ in their clinical setting. Survey responses were analyzed for trends.

Results: Overall, a common follow-up schedule was determined, which included an average of 6.8 appointments within the first year. Minor differences in training and programming practices between small and large $\mathrm{Cl}$ centers emerged; however, no statistically significant results were noted. Results did reveal trends in the use of certain clinical practices. This was particularly evident in the limited use of objective measures.

Conclusions: Overall, the findings support other recent studies that suggest the development of $\mathrm{Cl}$ guidelines that may standardize programming and follow-up practices of $\mathrm{Cl}$ audiologists. This could prove valuable for the continual improvement of $\mathrm{Cl}$ outcomes, particularly in the pediatric population.

Key Words: cochlear implants, pediatric, practice patterns

Abbreviations: $\mathrm{AB}=$ Advanced Bionics; $\mathrm{C}=$ comfort; $\mathrm{Cl}=$ cochlear implant; $\mathrm{ECAP}=$ electrically evoked compound action potential; ESRT = electrically evoked stapedial reflex threshold; IA = initial activation; $\mathrm{M}=$ most comfortable; $\mathrm{SD}=$ standard deviation; $\mathrm{T}=$ threshold

\section{INTRODUCTION}

$\mathrm{T}$ oday, more than 324,200 people benefit from cochlear implants (CIs) worldwide (NIDCD, 2013). However, there are myriad factors that can af- fect an individual's auditory skill outcomes after implantation including but not limited to: onset of the hearing loss (Geers et al, 2007), prelingual/postlingual deafness (Fryauf-Bertschy et al, 1992), age at implantation (Kirk et al, 2002), CI experience and auditory

*Department of Communication Sciences and Disorders, University of South Dakota, Vermillion, SD

Corresponding author: Jessica J. Messersmith, Department of Communication Sciences and Disorders, University of South Dakota, Vermillion, SD 57069; Email: jessica.messersmith@usd.edu

Portions of this work were presented at Audiology Now! 2016. Held in Phoenix, AZ, April 13-16, 2016. 
training (Moore and Teagle, 2002), residual hearing (Geers and Moog, 1989; Geers et al, 2007), spiral ganglion cell survival in auditory pathways (Sharma et al, 2002), cognitive abilities (Sarant et al, 2001; Geers et al, 2007), patient/family personality and motivation (Fadda, 2011), socioeconomic status (Geers et al, 2007; Chang et al, 2010), educational placement and mode of communication (Geers and Moog, 1989), parental involvement and commitment (Kirk et al, 2000; ASHA, 2003; Holt and Svirsky, 2008; AAA, 2013), quality of device programming (Shapiro and Bradham, 2012), and consistency of follow-up appointments (Moore and Teagle, 2002; Mertes and Chinnici, 2006; Carver, 2007). Despite the large variability in outcomes, great gains in speech perception and development of speech and language skills can be made following cochlear implantation (Bradham et al, 2009; AAA, 2013; NIH, 2013).

Although none of the aforementioned factors can singly predict success in the CI user, timely and consistent CI follow-up care and programming is a key contributor (Mertes and Chinnici, 2006; Carver, 2007). Follow-up care and programming play a large role in an individual's success as it ensures appropriate counseling, care of the device, troubleshooting, and provides fine tuning for increased access to the broad-spectrum of speech sounds needed for adequate speech perception and speech and language development (Hedley-Williams et al, 2003; Carver, 2007).

\section{PRACTICE PATTERNS}

A lthough there are suggested follow-up care schedules for CI users, there is no standardized schedule that delineates what procedures should be performed at specific appointment intervals. Several different followup schedules have been recommended in the literature that suggest that initial activation (IA) should occur anywhere from one to four weeks after surgery, with follow-up appointments occurring at different suggested intervals varying from every one to three months over the next one to two years (Carver, 2007; Bradham et al, 2009; Wolfe and Schafer, 2010; Shapiro and Bradham, 2012). In addition, there are no standardized guidelines for programming (i.e., what procedures are necessary during programming and at what appointment intervals they should occur). Although there are suggested guidelines and schedules in the literature, these documents are not specific in nature, several were published more than five years ago, and others are not necessarily based on scientific data.

Because there are no standardized guidelines for CI programming, clinical programming practices across providers and settings may be variable. Currently, there is limited research in the area of clinical practice patterns. A 2014 study (Uhler and Gifford, 2014) was conducted to gather information from CI centers on practices. Although some trends arose, the study reported that there was a lack of uniformity in the speech perception assessments used for children $<3$ years old. The study also showed that audiologists generally schedule follow-up visits every two to three months after the first year of implantation, and every six months thereafter. This study ultimately argued that establishing a pediatric version of the MSTB (2011) would prove increasingly beneficial in establishing consistency of care for individuals with CIs. Since that study was published, a minimum speech test battery for pediatric cochlear implant recipients has been proposed (Uhler et al, 2017).

A study by Vaerenberg et al (2014) distributed a world-wide inventory to $47 \mathrm{CI}$ centers in an attempt to gather data on current trends in CI programming and postoperative care schedules. Vaerenberg et al (2014) found that while there are some trends that emerged in programming and follow-up care, large variability in programming practices still exists. Important to note is that the study found that objective measures did not play a large role in determining map parameters, but rather, maps were most frequently based on subjective loudness judgments of the CI user. The study also reported that many centers were measuring electrical dynamic range on several electrodes and using streamlined programming measures on the remaining electrodes. Finally, the study suggested that a guide to common programming practices would prove useful in the fitting of CIs.

Lastly, a recent study by Moodie et al (2016) evaluated adherence to the best practice guidelines for pediatric hearing assessment and verification based on a survey of 350 audiologists in North America. This study concluded that audiologists working with the pediatric population must continue to cross-collaborate in the development, refinement, and dissemination of practice guidelines to maintain high quality, patient/familycentered care.

\section{POSSIBLE COMPONENTS OF COCHLEAR IMPLANT PROGRAMMING}

$R$ esearch shows that the more precise the map, the more potential there is for increased speech perception abilities (Shapiro and Bradham, 2012; Messersmith and Lockie, 2015). Basic mapping procedures involve setting Ts (threshold levels) and Cs (comfort levels) or Ms (most comfortable levels) across electrodes (Mertes and Chinnici, 2006; Wolfe and Schafer, 2010). The distance between the $\mathrm{T}$ and $\mathrm{C} / \mathrm{M}$ level at each electrode is the electrical dynamic range. These settings in the CI programing determine the range in which the acoustic sounds or the acoustic dynamic range are mapped to the electrical dynamic range and ultimately influences the individual's sound quality and speech recognition abilities (Wolfe and Schafer, 2010). 
At the current time, $\mathrm{T}$ and $\mathrm{C} / \mathrm{M}$ levels can be obtained using subjective feedback from the individual, such as behavioral loudness judgments, and/or by objective measurements, such as the electrically evoked stapedial reflex threshold (ESRT) or the electrically evoked compound action potential (ECAP). Given that persons with hearing loss can have difficulty making loudness judgments and sometimes cannot provide accurate, reliable feedback on the stimulus (Wolfe and Schafer, 2010); it may be beneficial to verify behaviorally measured C/M levels using objective measures that do not require the listener to make a loudness judgment (Hodges et al, 1997; Wolfe and Schafer, 2010). Each objective measure available relates differently to the electrical dynamic range. For example, ESRT has been found to strongly correlate with behavioral measures of C/M levels (Spivak et al, 1994; Hodges et al, 1997; Stephan and Welzl-Müller, 2000; Gross, 2003; Gordon et al, 2004) and as such can be used as a guide for the establishment of C/M levels. ECAP responses are not highly predictive of $\mathrm{T}$ or $\mathrm{C} / \mathrm{M}$ level, but rather demonstrate a verification of the level at which audible stimulation is obtained for a certain channel as they generally fall within the individual's electrical dynamic range. As such, ECAP can be useful for approximation of both $\mathrm{T}$ and C/M levels (Shapiro and Bradham, 2012). However, because of the weak relationship between ECAP measures and $\mathrm{T}$ and/or $\mathrm{C} / \mathrm{M}$ levels, alone they may not be sufficient for accurate approximation of psychophysical loudness perception (Hughes and Stille, 2008). They may, however, serve as a means of conditioning a CI user for T measures.

Gathering behavioral and/or objective measures for accurate programming can take a significant amount of time and numerous appointments. As more individuals continue to qualify for CIs, the case load of audiologists has increased; thus necessitating the need for more efficient programming measures. Streamlined measures such as interpolation and measuring groups of electrodes at a time have been incorporated into the programming software and recommended by the manufacturers (Cochlear Ltd., 2010; Wolfe and Schafer, 2010; AB, 2011; MED-EL, 2012). Some studies have evaluated the minimum number of electrodes to measure during objective and/or behavioral measurements. Results from these study support measuring a subset of electrodes; however, results suggest that measuring only one electrode, or a global increase of electrodes, is likely not sufficient (Plant et al, 2005; Messersmith and Lockie, 2015).

Another procedure that may be conducted during programming is loudness balancing (Wolfe and Schafer, 2010). Research demonstrates that maps with equal loudness percepts across channels results in improved sound quality and speech recognition when compared with maps with unbalanced C/M levels (Dawson et al, 1997). It is also important to mention that after objective and/or behavioral programming measurements, it may be relevant to check any changes in a user's map using live speech stimuli and the Ling 6 Sound test (six speech sounds that encompass speech frequencies from 250 to $8000 \mathrm{~Hz}$ ) (Ling, 1976; Ling, 1989; Zwolan and Stach, 2009).

Validation of the individual's CI programming through aided air conduction thresholds, aided speech perception testing, and patient/parent questionnaires is another procedure that may be conducted during postimplant appointments. Use of speech perception measures aid in tracking the individual's performance with the CI over time, identifying programming changes that may need to be made, and establishment of strategies for aural (re)habilitation. Validation measures provide a direct gauge of the individual's auditory benefit from the CI (Eisenberg, 2010). The Minimum Speech Test Battery for Adult Cochlear Implant Users (2011) has been in place to provide audiologists with a standardized test battery for the speech perception of adult CI users since 2011 (MSTB, 2011); the Pediatric Minimum Speech Test Battery was recently proposed (Uhler et al, 2017) with the same goal.

Although it is understood that the appropriateness of programming and follow-up care are key contributors to a CI user's success, there are no practice guidelines that specify the means for establishing electrical dynamic range, number of channels to be measured, use and application of objective measures, or appropriate follow-up schedule. With a lack of practice guidelines and limited published data on practice patterns in the cochlear implant clinic, the programming practices of providers are unknown. The purpose of this study was to identify the clinical practice patterns used by audiologists in the United States when programming and providing followup care to children who use CIs. This study sought to determine common pediatric programming approaches, the interval at which they are implemented, and follow-up schedules. This study holds significant implications for the governing bodies of audiology as results indicate a need to develop guidelines for CI programming. Also, this study provides access to an evidence basis of common programming practices in CI centers across the United States for those practicing $\mathrm{CI}$ audiologists currently providing care to pediatric CI users. Lastly, this study assists in continual improvement of outcomes for children with CIs by enhancing the standard of care for this population.

\section{METHODS}

\section{Participants}

Approval for this study was obtained from the Institutional Review Board at the University of South Dakota. Implied consent from the participants was inferred by voluntary completion of the survey. A total of 167 
participants opened and began the survey instrument, 113 of those completed the survey instrument. The survey's return rate was calculated using the 113 participants that completed the survey and the 471 participants to whom the instrument was successfully sent, providing a $23.99 \%$ rate of return.

\section{Procedures}

The target population for this survey included practicing audiologists who work with pediatric patients who use CIs throughout the United States. Participants were recruited by using the "find a clinic" function (MED-EL, $2013 ; \mathrm{AB}, 2015)$ or the "contact a hearing specialist" function (Cochlear Ltd., 2015) available on the manufacturers' websites. The "find a clinic" or "contact a hearing specialist" function allowed the investigator to enter a city, state, or zip code, and the website generated clinics within a specified radius surrounding that area. By use of this function, clinic names, phone numbers, addresses, and occasionally email addresses were obtained for CI centers across the nation. If the initial search using the "find a clinic" function did not yield an email address for a center, and/or no email address for the center was listed on the center's website, then a telephone call was made to the center requesting the $\mathrm{CI}$ audiologist(s) email address.

Using the "find a clinic" function for the three CI manufacturers, the investigator identified a total of 423 unique centers. Efforts were made to contact all 423 centers; successful contact was made with 349 centers and a list of 508 email addresses was compiled. A standard email was sent to the 508 email addresses that were able to be obtained. After this email, 37 email addresses were removed from the participant list for one of the following reasons: the individual reported that they were not an audiologist; the individual stated they were an audiologist but they do not specialize in pediatric CIs; staff stated that their center no longer provides CI services; individual reported that they are no longer employed at the respective CI center; or the e-mail was returned as undeliverable to the recipient. The email included an explanation of the study, a request to forward the email to the respective audiologist(s) that specialize in CIs (to combat the possibility that a general CI center email may be used), and a link to the survey in PsychData (Locke and Keiser-Clark, 2001). Two reminder emails were sent to 471 participants at two and four week intervals with respect to the initial invitation.

Respondents were informed in the cover letter that "the brief survey includes general questions regarding the geographic area in which you practice and the population in which you serve, the CI companies with which you work, the programming approaches you commonly use, and the typical follow-up care schedule implemented for a pediatric CI patient. To ensure reliability, please answer each question honestly and without referring to outside resources."
A Raosoft sample size calculator was used to calculate the necessary sample size for the survey. A 95\% confidence interval and $10 \%$ margin of error were specified to calculate the number of participants the study aimed to obtain. The recommended sample size was 81 (Raosoft Inc., 2004).

\section{Instrument}

This survey was developed by the study investigators. In an attempt to reduce errors and potential areas of confusion and increase content validity, the survey was reviewed by peers in the investigator's academic department. The survey was also reviewed by ten practicing audiologists who do not specialize in CIs and who had at least one year of clinic experience. Audiologists who did not specialize in CIs were used to maximize the number of audiologists who could participate in the study. Survey reviewers were asked to review the instrument for language and ease of read. Based on the reviewers' feedback, the survey was refined and the refined survey was disseminated to the participants of the study.

The first major content area of the survey included a cover letter introducing the investigators, purpose of the study, request for participation in the study, and instructions for completing the survey. The second major content area addressed clinic/provider demographics (e.g., private audiology practice, hospital, university, industry, other [specific]), average population of the area in which the clinic is located, clinic location (region of the country) (defined according to the U.S. Census Bureau, 2011), number of years practicing audiology, number of years specializing in CIs, average number of CI patients seen in a week, how many CI patients the center currently follows, percentage of pediatric CI patients, primary sources from which the provider received their training in CIs, and CI manufacturer(s) provider services.

The third major content section of the survey focused on the following general areas: (a) programming approaches that are commonly used when working with children with CIs, (b) the provision intervals for these procedures, (c) typical follow-up care schedule, and (d) assessments commonly used when completing validation measures. To assess these areas, multiple choice and open-ended questions related to the aforementioned areas were used. Logic was incorporated into the survey so that additional questions were presented based on the participant's answer to previous questions, specifically, respondents were only directed to questions pertaining to the CI manufacturer(s) they indicated programming. For questions related to programming approaches used, respondents were asked to indicate the percentage of pediatric patients the given approach has been used with. Examples of programming approaches included in the survey are as 
follows: impedance measures, ECAP (i.e., neural response imaging), ESRT, and behavioral loudness judgments. Procedures that would not be considered part of the CI programming (e.g., probe mic real-ear measurements) were also included. Questions targeted at eliciting the number of channels measured to establish electrical dynamic range, and typical follow-up care schedule were formatted as short answer/open ended. For validation tests (i.e., measures of speech perception), respondents were asked to complete a matrix of the measures used with various ages. The assessments included were those identified in Uhler and Gifford (2014). The survey instrument, in its entirety, is provided as Supplemental Appendix S1 (available with the online version of this article).

\section{RESULTS}

\section{Demographic Results}

A regional breakdown of the 113 respondents showed that 21 were from the West (19\%), 25 from the Midwest (22\%), 13 from the Northeast (12\%), 53 from the South (47\%), and 1 respondent was from the Pacific region (1\%). Approximately $55 \%$ of respondents had an Au.D., 26.5\% had a Ph.D., 15\% had a M.S./M.A., and 3.5\% had an Au.D./Ph.D. By region, the Au.D. was the most commonly reported degree, with the exception of the Midwest, where $10 \%$ reported having a Ph.D. and 9\%, an Au.D. In regard to participant age, approximately $15 \%$ ranged from 20 to $29,45 \%$ ranged in age from 30 to $39,18 \%$ ranged from 40 to 49 , and $22 \%$ were
$50+$. Distribution of age across region was relatively similar, with 30-39 being the most commonly reported age range across regions. The exception to this was in the Northeast, where more respondents were in the $50+$ age range. When asked about the number of years practicing audiology, results showed a relatively consistent distribution across ranges: $24 \%$ practicing $<5$ year, $25 \%$ practicing between six and ten year, $24 \%$ practicing between 11 and 20 years, and $27 \%$ practicing $>20$ years. These results were also relatively similar across regions, with the exception of the Northeast region, where results showed that more audiologists have been in the field longer (6\% in the $>20$ year range, $2 \%$ in the $11-20,1 \%$ in the $6-10$, and $3 \%$ in the $<5$ years range). This is consistent with the aforementioned result in regard to approximate age in the Northeast, with more respondents in the $50+$ range. In the Midwest, more audiologists have been in the field $<20$ years. With respect to how many years participants have been working with individuals who use CIs, $16 \%$ of respondents have been seeing CI patients for three years or less, $43 \%$ for three to ten years, and $41 \%$ for $10+$ years. See Figures 1 and 2 for respondent demographic data.

Audiologists responded that they received their training on CIs primarily from hands-on experience from another trained professional and manufacturerspecific trainings (Table 1). Results showed that both hands-on experience from another trained professional and manufacturer-specific training were ranked in the top three sources of CI training. However, for those practicing $<5$ years and those practicing six to ten

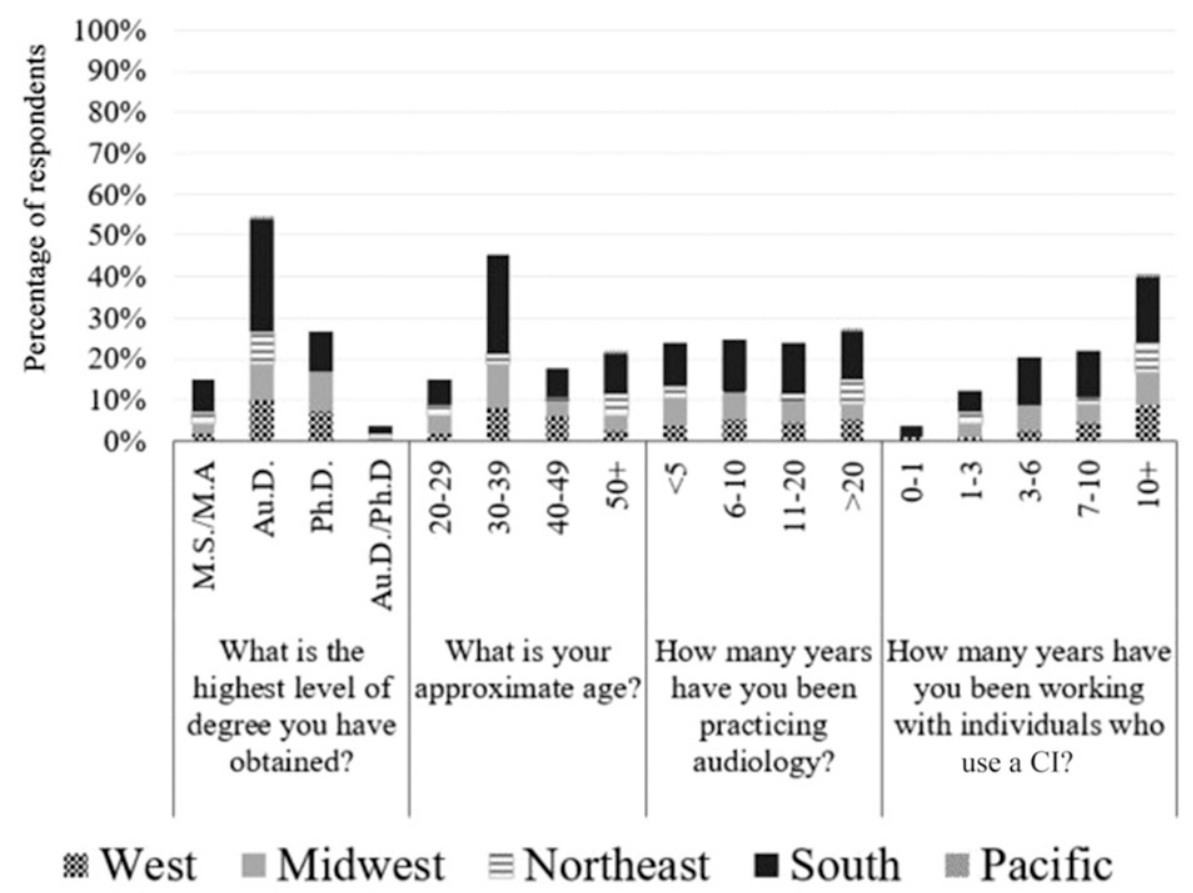

Figure 1. General demographic data by region. Percentage of total survey respondents is shown as a function of participant demographics. Region of the United States is shown by differences in shading. 


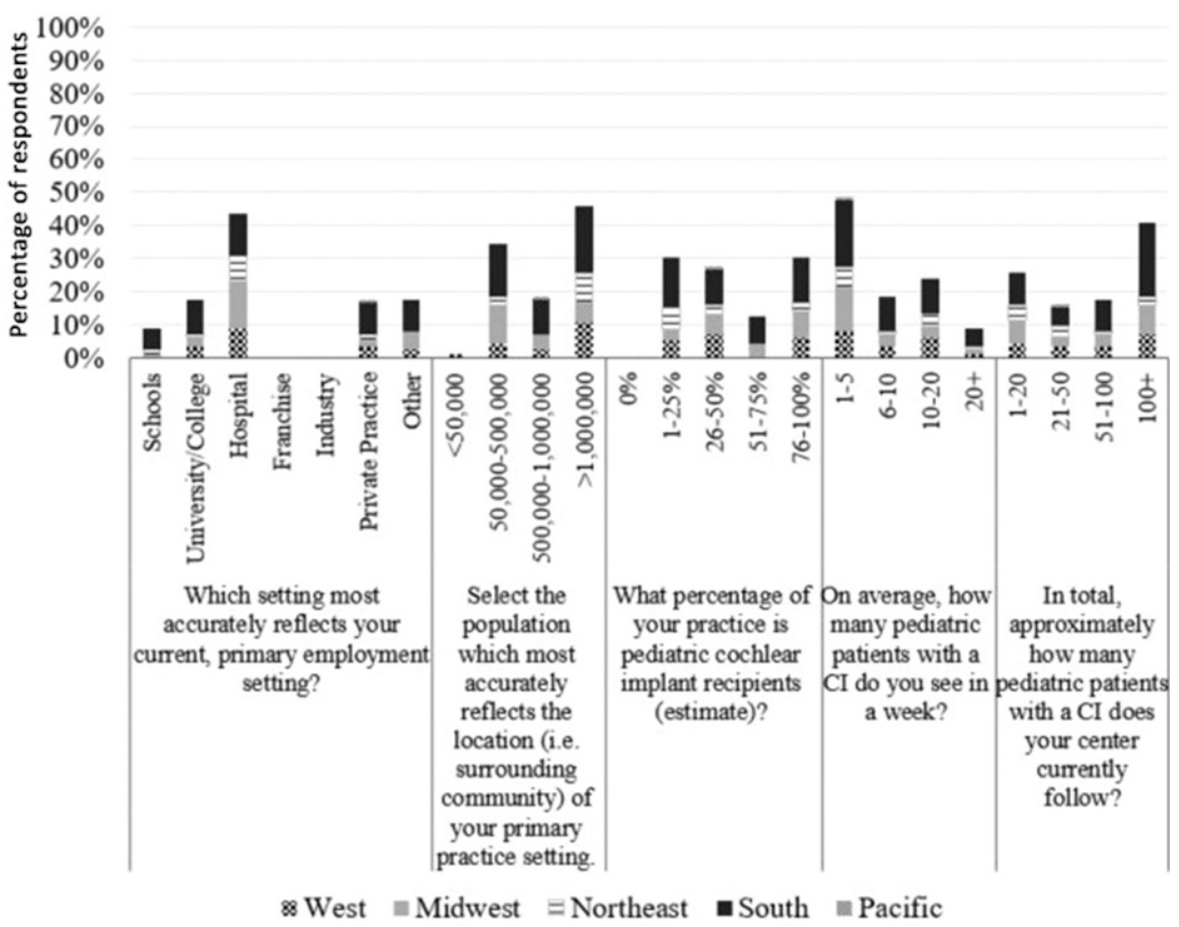

Figure 2. Specific demographic data by region. Percentage of total survey respondents is shown as a function of participant demographics. Region of the United States is shown by differences in shading.

years, the fourth year externship of their Au.D. program was typically ranked second and third in terms of training, respectively. There did not appear to be any differences in where CI training was received based on the region of the country nor the size of the CI center. An independent-samples $t$-test showed that there was not a significant difference between the sources of CI training (based on profile groupings based on top three selections) between small (following $<50$ pediatric patients) $(M=2.568$, standard deviation $[\mathrm{SD}]=1.265)$ and large (following $>50$ pediatric patients) $(M=2.286$, $\mathrm{SD}=1.288$ ) CI centers; $t(105)=1.124, p=0.263$. No correlation was found between the number of patients a CI center followed (size of CI center) and their reported sources of CI training (training profile) $(r=-0.150, \mathrm{n}=0.123$, $p=0.107$ ).

\section{Clinical Practices}

In terms of programming, results demonstrated trends in programming practices. A typical first year postimplantation follow-up schedule consisted of an average of 6.8 appointments (Figure 3). To allow for analysis of follow-up schedules, respondents' reported follow-up schedules were analyzed for similarities, and four similar follow-up schedules were identified. These similar follow-up schedules were numbered one through four; a fifth category was created for those follow-up schedules that did not fit into one of the four categories that were created based on similarity. Re- spondents were then grouped into one of these five follow-up schedule profiles, numbered one through five, according to which follow-up schedule they most closely aligned with. An independent-samples $t$-test, using these follow-up profiles determined there was not a significant difference between the typical follow-up care schedule between small $(M=2.292, \mathrm{SD}=0.999)$ and large $(M=2.333, \mathrm{SD}=1.215)$ CI centers; $t(79)=$ $-0.148, p=0.883$.

At a typical first year follow-up appointment, impedances appear to be run with almost all pediatric CI patients ( $89 \%$ of the time), behavioral loudness judgments (i.e., C/M levels) are conducted approximately $50 \%$ of the time, behavioral measures of $\mathrm{T}$ levels are measured approximately $43 \%$ of the time, and soundfield threshold testing about $26 \%$ of the time at a typical first year follow-up appointment (Figures 4 and 5). In terms of the appointment interval at which these procedures were reported as being completed, the aforementioned procedures were largely reported as being conducted at every appointment. At the IA for a pediatric CI recipient, ECAP measures appear to be the most commonly conducted assessment (41\%). Sound-field threshold testing and speech perception testing occurred most commonly at the one and three month appointments (about 18-30\%) and loudness balancing occurred most commonly at the one year post IA appointment $(20 \%)$. It is interesting to note that $54 \%$ of respondents report that they never conduct ESRT measurements. 


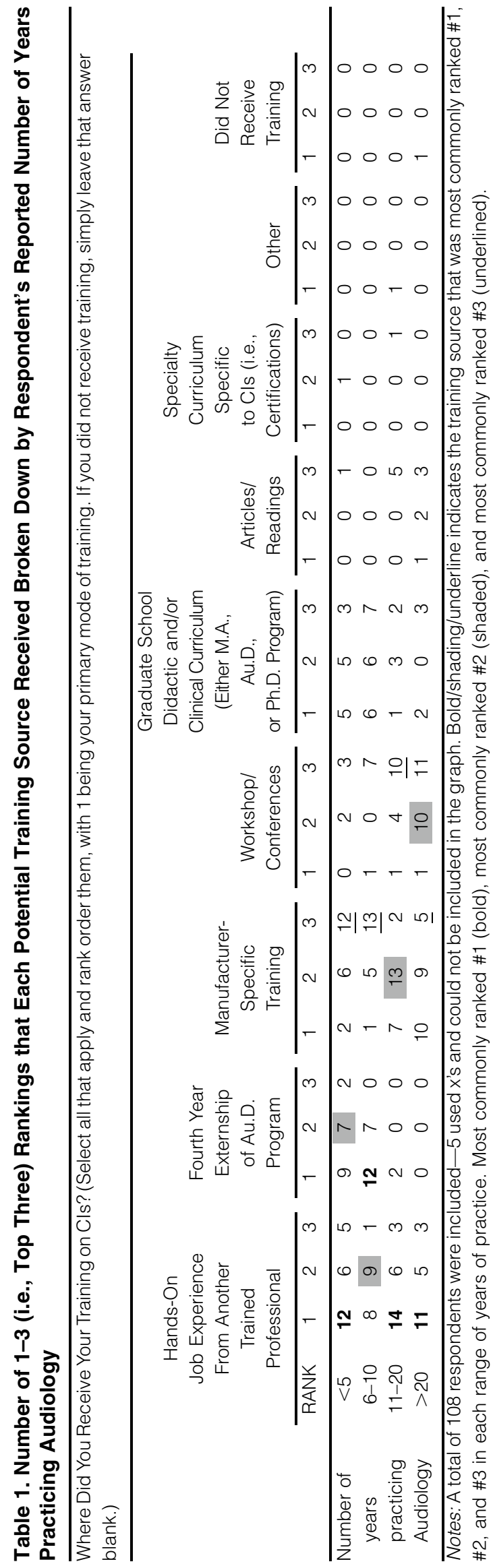

In terms of measurement of $\mathrm{T}$ levels, those respondents that reported working with cochlear measure on average 5-10 channels $(60 \%)$, those working with Advanced Bionics (AB) (51\%), and MED-EL (45\%) generally do not measure Ts. In regard to behavioral measures of loudness (i.e., C/M levels), those working with cochlear most commonly measure Cs on 5-10 channels (51\%). Those working with $\mathrm{AB}$ were more varied; $23 \%$ measure Ms on $5-10$, and $30 \%$, on $10+$ channels, whereas only $23 \%$ make these measures on $3-5$ channels (which include using speech bursts). Of those working with MED-EL, 26\% measure Ms on either 5-10 or $10+$ channels.

Lastly, this study sought to determine which assessments are commonly used when completing validation measures. Definite trends from this research emerged regarding common speech perception assessments and the age ranges with which they are used (assuming a typically developing child) (Table 2 ). In the five to ten years old category, about half of respondents reported using the Hearing in Noise Test-Children (Nilsson et al, 1996) most commonly, followed by the Pediatric AZ Bio Sentences (Spahr et al, 2014) and then PBK50 (Haskins, 1949). In the $>10$ years category, most of the respondents reported that they use the AZ Bio Sentences (Spahr et al, 2012), followed by a tie between the consonant-nucleus-consonant (CNC) word test (Peterson and Lehiste, 1962) and the Hearing in Noise Test (Nilsson et al, 1994).

\section{DISCUSSION}

Allow-up care and programming is known to play a $\boldsymbol{1}$ large role in an individual's success as it ensures appropriate counseling, care of the device, troubleshooting, and provides fine tuning for increased access to the broadspectrum of speech sounds needed for adequate speech perception and speech and language development (HedleyWilliams et al, 2003; Carver, 2007). This study sought to identify the clinical practice patterns used by audiologists in the United States when programming and providing follow-up care to children who use CIs.

Most of the audiologists working with pediatric CI recipients in the United States who participated in the study had an Au.D. and have been practicing $<10$ years. Furthermore, most of the pediatric CI centers appear to be located within an area of high population ( $>1,000,000$ people), commonly practicing in the hospital setting working with patients face-to-face. Although most of the audiologists indicated that training was primarily received on-the job and from manufacturers, more recent Au.D. graduates did rank training received during their fourth year externship as one of their primary sources of training. No age range of audiologists ranked graduate school clinical and/or didactic curriculum as a primary source of training. 


\begin{tabular}{|c|c|c|c|c|c|c|}
\hline & & & & $6-8$ & 9.11 & \\
\hline & 1 Week & 1 Month & 3 Months & Months & Months & 12 Months \\
\hline & Post IA & Post la & Post la & Post IA & Post IA & Post la \\
\hline
\end{tabular}

Figure 3. Reported typical follow-up care schedule for pediatric CI recipients within the first year postimplantation.

Given the expanding candidacy criteria for cochlear implantation and the increasing number of individuals implanted (Waltzman et al, 2002; Waltzman, 2006), it may be germane for audiology training programs to consider increasing the amount of education related to CIs.

When breaking down the follow-up data by manufacturer, it was noted that $90 \%, 93 \%$, and $93 \%$ of $\mathrm{AB}$, cochlear, and MED-EL respondents, respectively, reported conducting impedances measures with approximately $76-100 \%$ of their pediatric patients. Interestingly, impedance measures are run automatically with $\mathrm{AB}(\mathrm{AB}$, 2011), and with cochlear devices, the impedance measure is the first screen available upon opening the software. As such, it is unclear why there are approximately 7-10\% of audiologists who report not completing impedances. Perhaps children are not connected to programming software at every appointment.

Furthermore, approximately half of the audiologists reported conducting $\mathrm{C} / \mathrm{M}$ level measurements and T level measurements at every appointment. When combining these results with those broken down by manufacturer, results showed that over half of the audiologists for each manufacturer report conducting $\mathrm{C} / \mathrm{M}$ level measurements with their pediatric CI patients $76-100 \%$ of the time; however, three-quarter of audiologists reported conducting $\mathrm{T}$ level measurements with $76-100 \%$ of their pediatric patients with cochlear devices, whereas ap- proximately a quarter of audiologists reported conducting T measurements with MED-EL and AB devices. The aforementioned finding regarding $\mathrm{T}$ levels was appropriate because $\mathrm{T}$ levels do not necessarily have to be measured with $\mathrm{AB}$ and MED-EL devices (AB, 2011; Vaerenberg et al, 2014), but must be measured with cochlear devices (Cochlear Ltd., 2010).

With respect to measurement of $\mathrm{C} / \mathrm{M}$ levels, results showed that for $\mathrm{AB}$ devices, most audiologists reported measuring $\mathrm{M}$ levels on 5-10 channels. For cochlear, most audiologists reported that they measure $\mathrm{C}$ levels on 5-10 channels, and with MED-EL devices, one third of audiologists reported measuring $\mathrm{M}$ levels on $10+$ channels, and one-quarter of audiologists measure 5-10 channels. Considering the aforementioned findings, research has shown that the more precise the map is, the more potential there is for increased speech perception abilities (Shapiro and Bradham, 2012; Messersmith and Lockie, 2015). At least three, and more optimally at least five electrodes, should be measured behaviorally during streamlined programming (Plant et al, 2005). Furthermore, Messersmith and Lockie (2015) found that for AB users (Harmony, Neptune, or Platinum Series processors), the use of speech bursts did not produce significantly different results in speech perception scores than when every channel was measured, thus, those audiologists who are measuring five or more electrodes with their patients who use $A B$ devices may

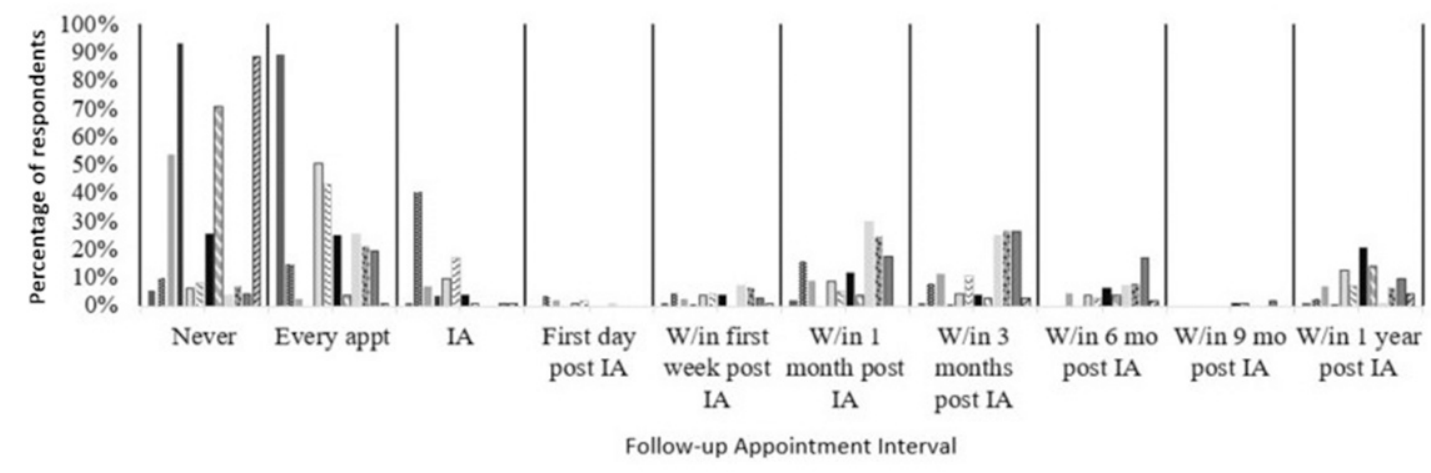

\begin{tabular}{|c|c|}
\hline - Impedance measures & ECAP (i.e. NRT, NRI, ART) \\
\hline ESRT & a eABR \\
\hline$\square$ Behavioral loudness judgments (i.e. C/M levels) & S Behavioral measures of threshold (i.e. T levels) \\
\hline - Loudness balancing (including loudness sweep) & $₫$ Pitch scaling \\
\hline Sound-field threshold testing & Speech reception threshold (SRT) \\
\hline
\end{tabular}

Figure 4. Follow-up appointment interval at which the above procedures are typically performed. Appointment intervals are indicated on the x-axis, with percentage of performance on the y-axis. The different assessments are represented by the different patterns of bars in the legend. 


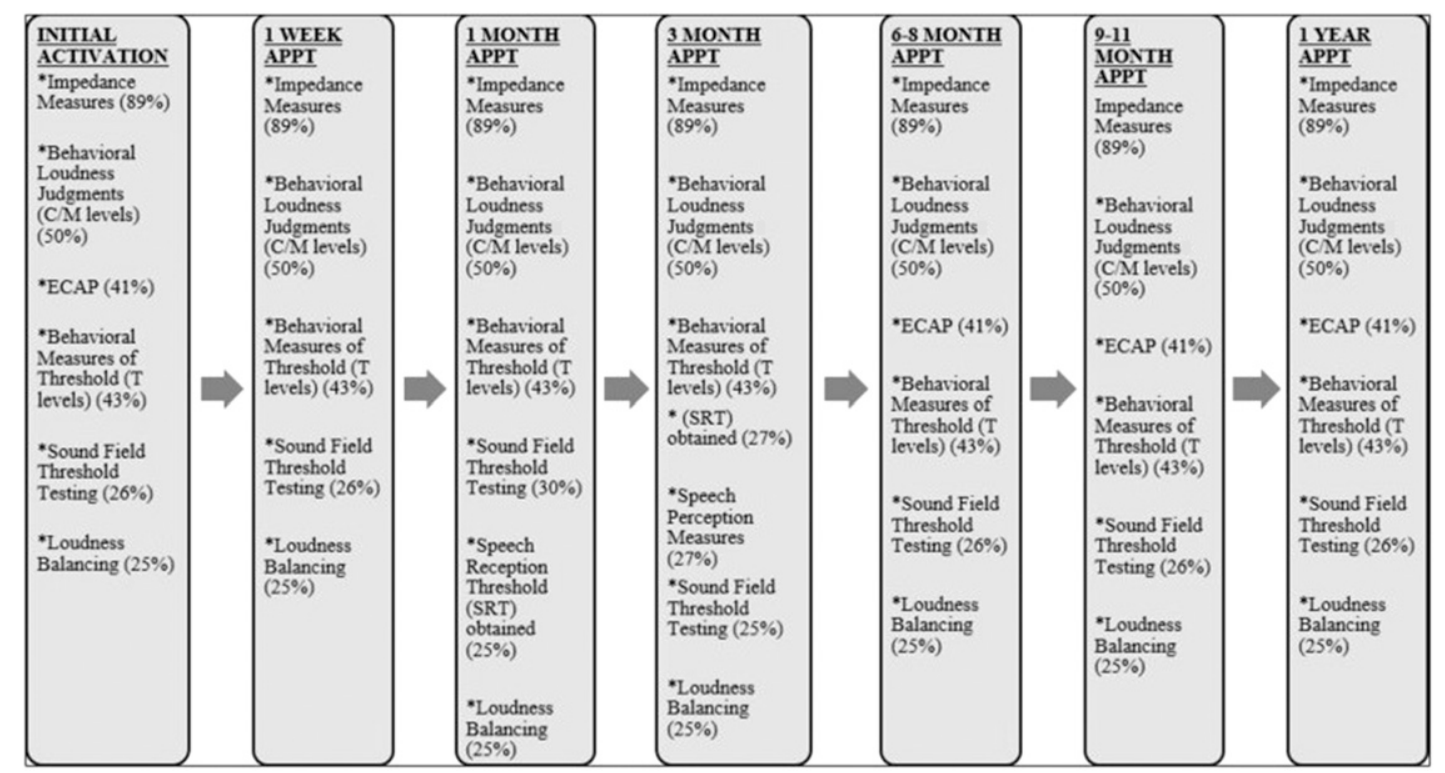

Figure 5. Depiction of the typical follow-up appointment schedule and a detail of the procedures reported to be most commonly conducted at each appointment interval. To be included in the above figure, a minimum of $25 \%$ of respondents had to report completing the measure at the specific interval.

be able to incorporate more streamlined practices. In addition, research has shown that loudness is impacted by the specific facets of the electrical stimulation (e.g., pulse width, pulse duration, pulse magnitude, and analog current) (Kiang and Moxon, 1972; Javel and Viemeister, 2000). Thus, the number of channels that are being stimulated can affect the perceived loudness of the stimulation. If speech bursts are used, the audiologist may need to make fewer adjustments in overall loudness once all electrodes are activated in live voice mode as compared to when loudness measurements are made on 5-10 or $10+$ individual channels.

Interestingly, despite manufacturer-specific training being ranked as the second most common source of training on CIs, it doesn't appear that the trends in programming practices necessarily align with the manufacturer recommendations regarding the basic mapping parameters needed for setting the C/M levels. For example, use of speech bursts (which indicates measuring four groups of electrodes) for setting $M$ levels with $A B$ devices is the manufacturer-recommended practice (AB, 2011). With cochlear devices, the clinical guidance document discusses the use of their streamlined programming measures which includes a default of five behavioral measurements. The document states that the streamlined programming measures can simplify the programming process without compromising the integrity of the map (Cochlear Ltd., 2010; 2014). MED-EL's Quick Fitting Guide recommends that upon initial fit, a global increase in MCLs (most comfortable levels) (similar to $\mathrm{C} / \mathrm{M}$ levels for cochlear and $\mathrm{AB}$, respectively) as a place to start, and the shift and tilt function can be used to adjust as needed based on the patient report (MEDEL, 2015). MED-EL's software also includes an interpolation button which can be used to estimate levels on channels that behavioral measurements were not directly measured on (MED-EL, 2012).

The average number of appointments within the first year was 6.8, which was similar to results from Vaerenberg et al (2014) which showed that, of their respondents, (47 CI centers worldwide), 30\% conduct 5-6 follow-up appointments and 36\% conduct 7-8 follow-up sessions. Results from Uhler and Gifford (2014) also aligned similarly to the aforementioned research. Uhler and Gifford's found that after IA, participants either followed-up weekly or biweekly transitioning to follow-up appointments every three months. Through results from this study, a typical follow-up appointment schedule was compiled. This follow-up schedule included a one week post IA appointment, a one month post IA appointment, a three month post IA appointment, a six to eight months post IA appointment, a 9-11 post IA appointment, and a 12 months post IA appointment.

When comparing programming practices in small versus large CI centers, several differences were highlighted. Results showed that a higher percentage of small centers versus large centers report never doing ESRT, and a higher percentage of small centers reported doing ECAP at the IA appointment when compared with large centers. Furthermore, more audiologists from smaller centers versus larger centers reported that they never perform loudness balancing measures. However, no significant difference in source of CI training or 
follow-up schedule was shown between small and large CI centers. These differences between large and small CI centers are interesting to consider with respect to optimizing the CI fitting, although basic $\mathrm{T}$ and $\mathrm{C} / \mathrm{M}$ measures may be adequate for creating a CI MAP. Utilization of clinical tools such as objective measures and loudness balancing can increase the audiologist's confidence in the appropriateness of the CI fitting and the optimization of loudness across the electrode array. For example, ESRT measurements have been shown to be highly correlated with $\mathrm{C} / \mathrm{M}$ levels (Hodges et al, 1997; Stephan and Welzl-Müller, 2000; Gross, 2003; Gordon et al, 2004), they are generally stable across the electrode array (Caner et al, 2007), and they have proved to be stable over time, especially when compared with stability of behavioral C/M levels over time (Spivak et al, 1994). Thus, ESRT may be beneficial to incorporate into cochlear implant programming care, and the measurements would likely not need to be completed at every appointment as they are stable over time, which would aid CI audiologists in developing effective, streamlined programming methods.

As previously stated, gains in speech perception and speech and language skills can be made with a CI (Bradham et al, 2009; AAA, 2013; NIH, 2013). Although many factors contribute to these gains, factors within the control of the CI audiologist are in play. Specifically, quality of device programming (Shapiro and Bradham, 2012) and consistency of follow-up appointments (Moore and Teagle, 2002; Mertes and Chinnici, 2006; Carver, 2007) have been shown to impact outcomes with a CI. Provision of a consistent programming protocol and follow-up schedule across CI clinics is likely to enhance the quality of device programming and increase regular follow-up appointments, thereby increasing gains in speech perception and speech and language development.

Given the lack of a standard practice guidelines document for CI programming and results from this study and others (Uhler and Gifford, 2014; Vaerenberg et al, 2014) demonstrating variability in CI clinical programming practices across centers, an evidence-based, standardized best practice CI programming guidelines would be beneficial to the field. It is possible that the variability observed with respect to outcomes of current CI users is in part reflective of this variability in programming practices across CI centers. As such, current outcomes for individuals who use a CI, specifically pediatrics, may not be an accurate representation of the full potential for success with a CI. Ultimately, the results of this study, as well as the aforementioned studies, support the argument for an updated and standardized best practice document for cochlear implant programming. 


\section{REFERENCES}

Advanced Bionics. (2011) SoundWave 2.1: Quick Reference Cards. Retrieved from http://www.advancedbionics.com/content/dam/ ab/Global/en_ce/documents/professional/AB_SoundWave_2.1_Quick_ Reference_Cards.pdf. Accessed February 4, 2014.

Advanced Bionics. (2015) Find a Clinic [Interactive Map of Cochlear Implant Clinics Registered with Advanced Bionics]. Retrieved from https://www.advancedbionics.com/content/advancedbionics/au/en/home/ about-cochlear-implants/find-a-clinic.html. Accessed August 22, 2017.

American Academy of Audiology. (2013) Cochlear Implants in Children. Retrieved from http://www.audiology.org/resources/ documentlibrary/pages/cochlearchildren.aspx. Accessed March 9, 2015.

American Speech-Language-Hearing Association. (2003) Technical Report: Cochlear Implants. Retrieved from http://www.asha. org/policy/TR2004-00041/. Accessed September 25, 2014.

Bradham T, Snell G, Haynes D. (2009) Current practices in pediatric cochlear implantation. Perspect Hear Hear Disord Child 19: $32-42$.

Caner G, Olgun L, Gültekin G, Balaban M. (2007) Optimizing fitting in children using objective measures such as neural response imaging and electrically evoked stapedius reflex threshold. Otology and Neurotology 28(5):637-640.

Carver C. (2007) Cochlear implant mapping: what every CI user and candidate should know. Hearing Loss Magazine 28(4):10-13.

Chang DT, Ko AB, Murray GS, Arnold JE, Megerian CA. (2010) Lack of financial barriers to pediatric cochlear implantation: impact of socioeconomic status on access and outcomes. Arch Otolaryngol Head Neck Surg 136(7):648-657.

Cochlear Ltd. (2010) Clinical Guidance Document. Retrieved from http://cochlear-cee-training.org/wordpress/wp-content/uploads/ 2011/12/231495_ISS3_EN_CSS_Clinical_Guidance_Document. pdf. Accessed February 4, 2014.

Cochlear Ltd. (2014) Custom Sound 4.1 Software User Guide. Retrieved from http://www.cochlear.com/wps/wcm/connect/0e264406f2fd-4a69-b37e7c5919d01351/en_product_css_4.1_sp3_userguide_54 0440_1.01_june2014_1.05mb.pdf?MOD=AJPERES\&CACHEID = 0e264406-f2fd-4a69-b37e-7c5919d01351. Accessed February 4, 2014.

Cochlear Ltd. (2015) Contact a Hearing Specialist [Interactive Map of Cochlear Implant Clinics Registered with Cochlear Ltd.]. Retrieved from http://www.cochlear.com/wps/wcm/connect/us/home/ take-the-next-step/contact-a-hearing-specialist. Accessed August $22,2017$.

Dawson PW, Skok M, Clark GM. (1997) The effect of loudness imbalance between electrodes in cochlear implant users. Ear Hear 18(2):156-165.

Eisenberg LS. (2010) Measuring auditory performance of Pediatric cochlear implant users: what can be learned for children who use hearing instruments? Presentation at the Meeting of the International Pediatric Conference "A Sound Foundation through Early Amplification," Chicago, IL.

Fadda S. (2011) Psychological aspects when counseling families who have children with cochlear implants. J Matern Fetal Neonatal Med 24(Suppl 1):104-106.

Fryauf-Bertschy H, Tyler RS, Kelsay DM, Gantz BJ. (1992) Performance over time of congenitally deaf and postlingually deafened children using a multichannel cochlear implant. $J$ Speech Hear Res 35(4):913-920.
Geers A, Moog J. (1989) Factors predictive of the development of literacy in profoundly hearing impaired adolescents. Volta Review 91:69-85.

Geers AE, Nicholas JG, Moog JS. (2007) Estimating the influence of cochlear implantation on language development in children. Audiol Med 5(4):262-273.

Gordon KA, Papsin BC, Harrison RV. (2004) Toward a battery of behavioral and objective measures to achieve optimal cochlear implant stimulation levels in children. Ear Hear 25(5):447-463.

Gross A. (2003) Fitting Techniques for the Pediatric Cochlear Implant Patient. Retrieved from http://www.audiologyonline.com/ articles/fitting-techniques-for-pediatric-cochlear-1128. Accessed March 13, 2014.

Haskins J. (1949) A phonetically balanced test of speech discrimination for children (unpublished master's thesis). Evanston, IL: Northwestern University.

Hedley-Williams AJ, Sladen DP, Tharpe A. (2003) Programming, care, and troubleshooting of cochlear implants for children. Top Lang Disord 23(1):46-56.

Hodges AV, Balkany TJ, Ruth RA, Lambert PR, Dolan-Ash S, Schloffman JJ. (1997) Electrical middle ear muscle reflex: use in cochlear implant programming. Otolaryngol Head Neck Surg 117(3 Pt 1):255-261.

Holt RF, Svirsky MA. (2008) An exploratory look at pediatric cochlear implantation: Is earliest always best? Ear Hear 29(4):492-511.

Hughes ML, Stille LJ. (2008) Psychophysical versus physiological spatial forward masking and the relation to speech perception in cochlear implants. Ear Hear 29(3):435-452.

Javel E, Viemeister NF. (2000) Stochastic properties of cat auditory nerve responses to electric and acoustic stimuli and application to intensity discrimination. J Acoust Soc Am 107(2):908-921.

Kiang NY, Moxon EC. (1972) Physiological considerations in artificial stimulation of the inner ear. Ann Otol Rhinol Laryngol 81(5): $714-730$.

Kirk KI, Miyamoto RT, Lento CL, Ying E, O’Neill T, Fears B. (2002) Effects of age at implantation in young children. Ann Otol Rhinol Laryngol Suppl 189:69-73.

Kirk KI, Miyamoto RT, Ying EA, Perdew AE, Zuganelis H. (2000) Cochlear implantation in young children: effect of age at implantation and mode of communication. Volta Review 102(4):127-144.

Ling D. (1976) Speech and the Hearing-Impaired Child: Theory and Practice. Washington, DC: Alexander Graham Bell Association for the Deaf.

Ling D. (1989) Foundations of Spoken Language for the HearingImpaired Child. Washington, DC: Alexander Graham Bell Association for the Deaf.

Locke B, Keiser-Clark D. (2001) PsychData. Retrieved from URL. https://www.psychdata.com/default.asp. Accessed April 3, 2014.

MED-EL. (2012) Maestro System Software. Retrieved from http://www. medel.com/products-software-maestro/. Accessed December 22, 2014.

MED-EL. (2013) Find a Clinic [Interactive Map of Cochlear Implant Clinics Registered with MED-EL]. Retrieved from http:// www.medel.com/us/clinic-finder/. Accessed December 22, 2014.

MED-EL. (2015). Quick Fitting Guide for Opus 2, Rondo \& Sonnet with Maestro 6.0. Innsbruck, Austria: MED-EL. Print. 
Mertes J, Chinnici J. (2006) Cochlear Implants- Considerations in Programming for the Pediatric Population. Retrieved from http:// www.audiologyonline.com/articles/cochlear-implants-considerations-in programming-1011.

Messersmith JJ, Lockie J. (2015, April) Evaluation of streamlined programming measures in children with cochlear implants. Poster presented at the annual meeting of the American Academy of Audiology, San Antonio, TX.

Minimum Speech Test Battery (MSTB). (2011) Minimum Speech Test Battery for Adult Cochlear Implant Users 2011: Version 1.0. Retrieved from http://www.auditorypotential.com/ MSTBfiles/MSTBManual2011-06-20\%20.pdf. Accessed March 11,2014

Moodie S, Rall E, Eiten L, Lindley G, Gordey D, Davidson L, Bagatto M, Scollie S. (2016) Pediatric audiology in North America: current clinical practice and how it relates to the american academy of audiology pediatric amplification guideline. $J$ Am Acad Audiol 27(3):166-187.

Moore JA, Teagle HF. (2002) An introduction to cochlear implant technology, activation, and programming. Lang Speech Hear Serv Sch 33(3):153-161.

National Institute on Deafness and Other Communication Disorders, National Institutes of Health. (2013) Cochlear Implants (NIH Publication No. 11-4798). Retrieved from https://www.nidcd.nih.gov/ health/hearing/pages/coch.aspx. Accessed August 22, 2017.

National Institutes of Health. (2013) Cochlear Implants. Retrieved from http://report.nih.gov/nihfactsheets/ViewFactSheet.aspx?csid=83. Accessed March 9, 2015.

Nilsson M, Soli SD, Sullivan JA. (1994) Development of the hearing in noise test for the measurement of speech reception thresholds in quiet and in noise. J Acoust Soc Am 95(2):1085-1099.

Nilsson MJ, Soli SD, Gelnett DJ. (1996) Development of the Sharing in Noise Test for Children (HINT-C). Los Angeles, CA: House Ear Institute.

Peterson GE, Lehiste I. (1962) Revised CNC lists for auditory tests. J Speech Hear Disord 27:62-70.

Plant K, Law M, Whitford L, Knight M, Tari S, Leigh J, Pedley K, Nel E. (2005) Evaluation of streamlined programming procedures for the Nucleus cochlear implant with the contour electrode array. Ear Hear 26(6):651-668.

Raosoft, Inc. (2004) Sample Size Calculator. Retrieved from http:// www.raosoft.com/samplesize.html. Accessed February 5, 2015.

Sarant JZ, Blamey PJ, Dowell RC, Clark GM, Gibson WP. (2001) Variation in speech perception scores among children with cochlear implants. Ear Hear 22(1):18-28.

Shapiro WH, Bradham TS. (2012) Cochlear implant programming. Otolaryngol Clin North Am 45(1):111-127.
Sharma A, Dorman M, Spahr A. (2002) A sensitive period for the development of the central auditory system in children with cochlear implants: implications for age of implantation. Ear Hear 23(6):532-539.

Spahr AJ, Dorman MF, Litvak LM, Van Wie S, Gifford RH, Loizou PC, Loiselle LM, Oakes T, Cook S. (2012) Development and validation of the AzBio sentence lists. Ear Hear 33(1):112-117.

Spahr AJ, Dorman MF, Litvak LM, Cook SJ, Loiselle LM, DeJong MD, Hedley-Williams A, Sunderhaus LS, Hayes CA, Gifford RH. (2014) Development and validation of the pediatric AzBio sentence lists. Ear Hear 35(4):418-422; Advance online publication doi:10.1097/AUD.0000000000000031

Spivak LG, Chute PM, Popp AL, Parisier SC. (1994) Programming the cochlear implant based on electrical acoustic reflex thresholds: patient performance. Laryngoscope 104(10):1225-1230.

Stephan K, Welzl-Müller K. (2000) Post-operative stapedius reflex tests with simultaneous loudness scaling in patients supplied with cochlear implants. Audiology 39(1):13-18.

Uhler K, Gifford RH. (2014) Current trends in pediatric cochlear implant candidate selection and postoperative follow-up. Am J Audiol 23(3):309-325.

Uhler K, Warner-Czyz A, Gifford R; Working Group. (2017) Pediatric minimum speech test battery. J Am Acad Audiol 28(3):232-247.

U.S. Census Bureau. (2011) [Graphic Map Illustration] Census Bureau Regions and Division with State FIPS Codes. Retrieved from https://www.census.gov/geo/maps-data/maps/pdfs/reference/ us_regdiv.pdf. Accessed November 17, 2016.

Vaerenberg B, Smits C, De Ceulaer G, Zir E, Harman S, Jaspers N, Tam Y, Dillon M, Wesarg T, Martin-Bonniot D, Gärtner L, Cozma S, Kosaner J, Prentiss S, Sasidharan P, Briaire JJ, Bradley J, Debruyne J, Hollow R, Patadia R, Mens L, Veekmans K, Greisiger R, Harboun-Cohen E, Borel S, Tavora-Vieira D, Mancini P, Cullington $\mathrm{H}, \mathrm{Ng} \mathrm{AH}$, Walkowiak A, Shapiro WH, Govaerts PJ. (2014) Cochlear implant programming: a global survey on the state of the art. Scientific World Journal 2014: 501738 .

Waltzman SB. (2006) Cochlear implants: current status. Expert Rev Med Devices 3(5):647-655.

Waltzman SB, Roland JT Jr, Cohen NL. (2002) Delayed implantation in congenitally deaf children and adults. Otol Neurotol 23(3):333-340

Wolfe J, Schafer EC. (2010) Programming Cochlear Implants: A Volume in the Core Clinical Concepts in Audiology Series. San Diego, CA: Plural Publishing.

Zwolan TA, Stach CJ. (2009) Programming cochlear implant systems. In: Eisernberg LS, ed. Clinical Management of Children with Cochlear Implants. San Diego, CA: Plural Publishing, 113-131. 


\section{Supplemental Appendix S1}

\section{INVESTIGATION OF CURRENT NATIONWIDE COCHLEAR IMPLANT CLINICAL PRACTICE PATTERNS}

*1) What is the highest level of degree you have obtained?

a. M.S./M.A. [Value=1]

b. Au.D. [Value=2]

c. Ph.D [Value $=4]$

d. Au.D/Ph.D. [Value=3]

*2) What is your approximate age?

Oa. 20-29 [Value=1]

b. 30-39 [Value=2]

c. $40-49$ [Value=3]

d. $50+[$ Value $=4]$

3) Which setting most accurately reflects your current, primary employment setting?

$\square$ a. Schools [Checked=1]

$\square$ b. University/college [Checked=1]

$\square$ c. Hospital [Checked=1]

$\square$ d. Franchise [Checked=1]

$\square$ e. Industry [Checked=1]

$\square$ f. Private practice [Checked=1]

$\square$ g. Other (please specify) [Checked=1]

*4) In what region of the country is your clinic located?

$\bigcirc$ a. West [Value $=1$ ]

$\bigcirc$ b. Midwest [Value=2]

c. Northeast [Value=3]

d. South [Value=4]

e. Pacific [Value=5] 


\section{Supplemental Appendix S1}

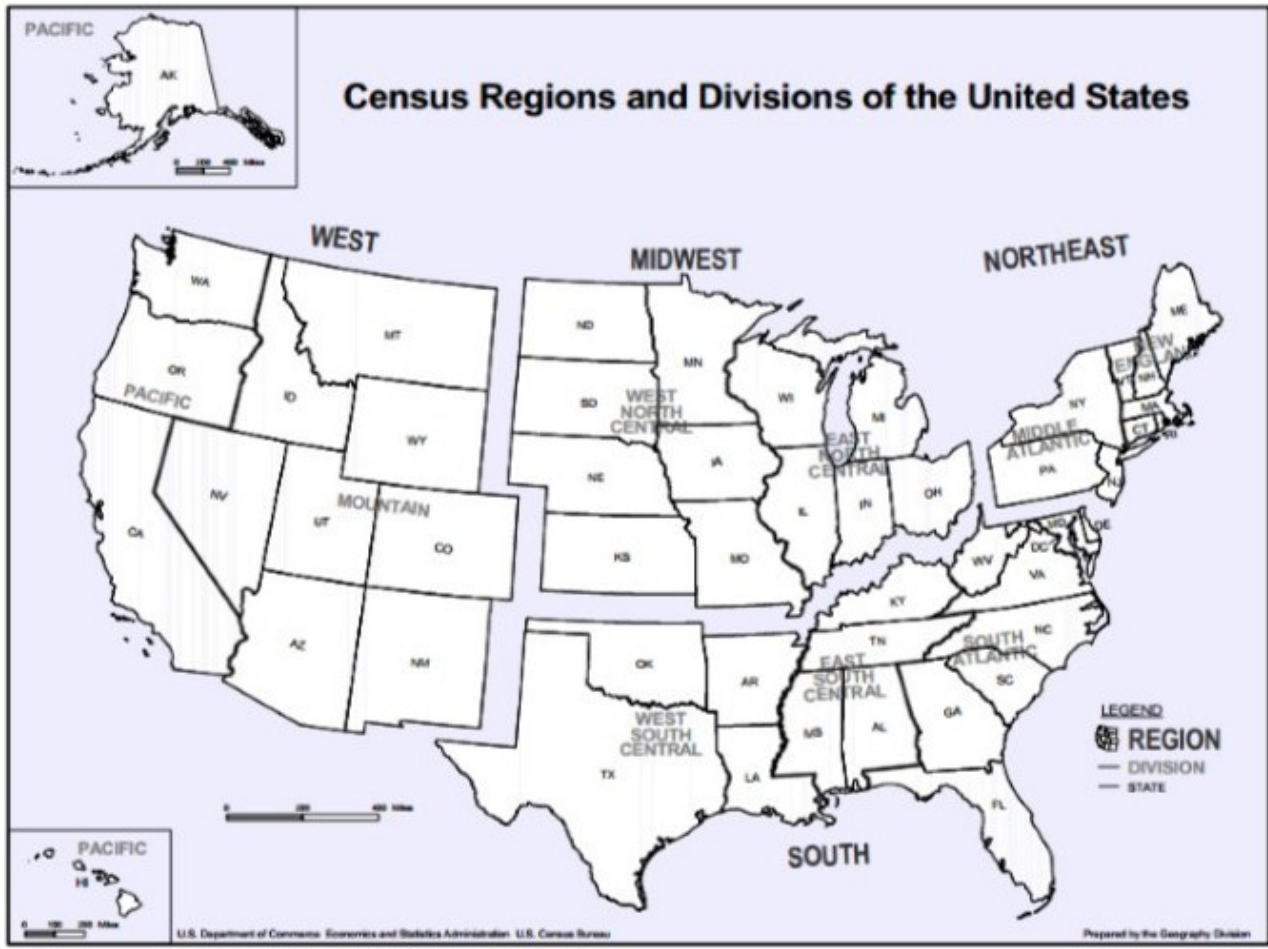

U.S. Census Bureau. (2011). [Graphic map illustration] Census bureau regions and division with state FIPS codes. Retrieved from: https://www.census.gov/geo/mapsdata/maps/pdfs/reference/us_regdiv.pdf

Select the percentage of time that you interact with patients in the following manners:

*5) Face to face in office

$\begin{array}{ccccc}\bigcirc 0 \% & \bigcirc 1-25 \% & \bigcirc 26-50 \% & \bigcirc 51-75 \% & \bigcirc 76-100 \% \\ {[\text { [Value=1] }} & {[\text { Value=2] }} & \text { [Value=3] } & \text { [Value=4] } & \text { [Value=5] }\end{array}$

*6) Home-based

$\begin{array}{ccccc}\bigcirc 0 \% & \bigcirc 1-25 \% & \bigcirc 26-50 \% & \bigcirc 51-75 \% & \bigcirc 76-100 \% \\ {[\text { Value=1] }} & {[\text { Value=2] }} & {[\text { Value=3] }} & {[\text { Value=4] }} & {[\text { Value=5] }}\end{array}$

*7) Tele-audiology

$\begin{array}{ccccc}\bigcirc 0 \% & O 1-25 \% & O 26-50 \% & O 51-75 \% & \bigcirc 76-100 \% \\ {[\text { [Value=1] }} & {[\text { Value=2] }} & \text { [Value=3] } & {[\text { Value=4] }} & \text { [Value=5] }\end{array}$

*8) Other

$\begin{array}{ccccc}\bigcirc 0 \% & \bigcirc 1-25 \% & \bigcirc 26-50 \% & \bigcirc 51-75 \% & \bigcirc 76-100 \% \\ {[\text { [Value=1] }} & {[\text { Value=2] }} & \text { [Value=3] } & \text { [Value=4] } & \text { [Value=5] }\end{array}$

*9) Select the population which most accurately reflects the location (i.e. surrounding community) of your primary practice setting.

a. $<50,000$ [Value $=1$ ]

b. 50,000-500,000 [Value=2]

c. $500,000-1,000,000$ [Value=3]

$\bigcirc$ d. $>1,000,000$ [Value $=4]$

*10) How many years have you been practicing audiology?

a. $<5$ [Value=1] 


\title{
Supplemental Appendix S1
}

\author{
b. 6-10 [Value=2] \\ C. 11-20 [Value=3] \\ d. $>20$ [Value $=4]$
}

*11) How many years have you been working with individuals who utilize a cochlear implant $(\mathrm{Cl})$ ?
a. $0-1$ [Value $=1]$
b. 1-3 [Value=2]
c. 3-6 [Value=3]
d. $7-10$ [Value $=4]$
e. $10+[$ Value $=5]$
f. I never work with individuals with $\mathrm{Cls}$ [Value=6]

\section{Question Logic}

If [a. $\mathbf{0}-1]$ is selected, then skip to question [No logic applied]

If [b. 1-3] is selected, then skip to question [No logic applied]

If [c. 3-6] is selected, then skip to question [No logic applied]

If [d. 7-10] is selected, then skip to question [No logic applied]

If [e. 10+] is selected, then skip to question [No logic applied]

If [f. I never work with individuals with Cls...] is selected, then skip to question [GO TO END OF SURVEY]

*12) What percentage of your practice is pediatric cochlear implant recipients (estimate)?

a. $0 \%$ [Value $=1]$

b. $1-25 \%$ [Value=2]

c. $26-50 \%$ [Value $=3]$

d. $51-75 \%$ [Value $=4]$

e. $76-100 \%$ [Value $=5]$

\section{Question Logic}

If [a. $\mathbf{0 \%}$ ] is selected, then skip to question [GO TO END OF SURVEY]

If [b. $\mathbf{1 - 2 5 \%}$ ] is selected, then skip to question [No logic applied]

If [c. $26-50 \%$ ] is selected, then skip to question [No logic applied]

If [d. $\mathbf{5 1 - 7 5 \%}$ ] is selected, then skip to question [No logic applied]

If [e. $\mathbf{7 6 - 1 0 0 \% ]}$ is selected, then skip to question [No logic applied]

*13) On average, how many pediatric patients with a $\mathrm{Cl}$ do you see in a week?
Oa. 1-5 [Value=1]
Ob. 6-10 [Value=2]
c. $10-20$ [Value=3]
Od. 20+ [Value $=4]$

*14) In total, approximately how many pediatric patients with a $\mathrm{Cl}$ does your center currently follow?
Oa. 1-20 [Value=1]
b. 21-50 [Value=2]
C. $51-100$ [Value $=3]$
Od. $100+[$ Value $=4]$

15) Where did you receive your training on Cls? (select all that apply and rank order them, with 1 being your primary mode of training. If you did not receive training, simply leave that answer blank.)

a. Graduate School didactic and/or clinical curriculum (either M.A., Au.D., or Ph.D. program)

b. 4th year externship of Au.D. program"

c. Hands-on job experience from another trained professional

d. Specialty curriculum specific to Cls (i.e. certifications)

e. Manufacturer specific training

f. Workshop/conferences 


\title{
Supplemental Appendix S1
}

\author{
g. Articles/readings \\ h. Other \\ i. Did not receive training
}

16) In the above question, if you selected "other" as a mode of training on Cls, please specify the setting in which that training was received. If you did not select "other," simply leave this question blank.

The next portion of the survey will include a set of questions regarding each of the three $\mathrm{Cl}$ manufacturers (Advanced Bionics, Cochlear Corporation, MED-EL).

*17) Do you work with Advanced Bionics (AB) devices?
a. yes- often [Value=1]
b. rarely [Value $=2$ ]
c. never [Value $=3$ ]

Question Logic

If [a. yes- often] is selected, then skip to question [No logic applied]

If [b. rarely] is selected, then skip to question [No logic applied]

If [c. never] is selected, then skip to question [\#32]

Page Break

With what percentage of your pediatric patients that use AB devices do you use each of the following approaches with:

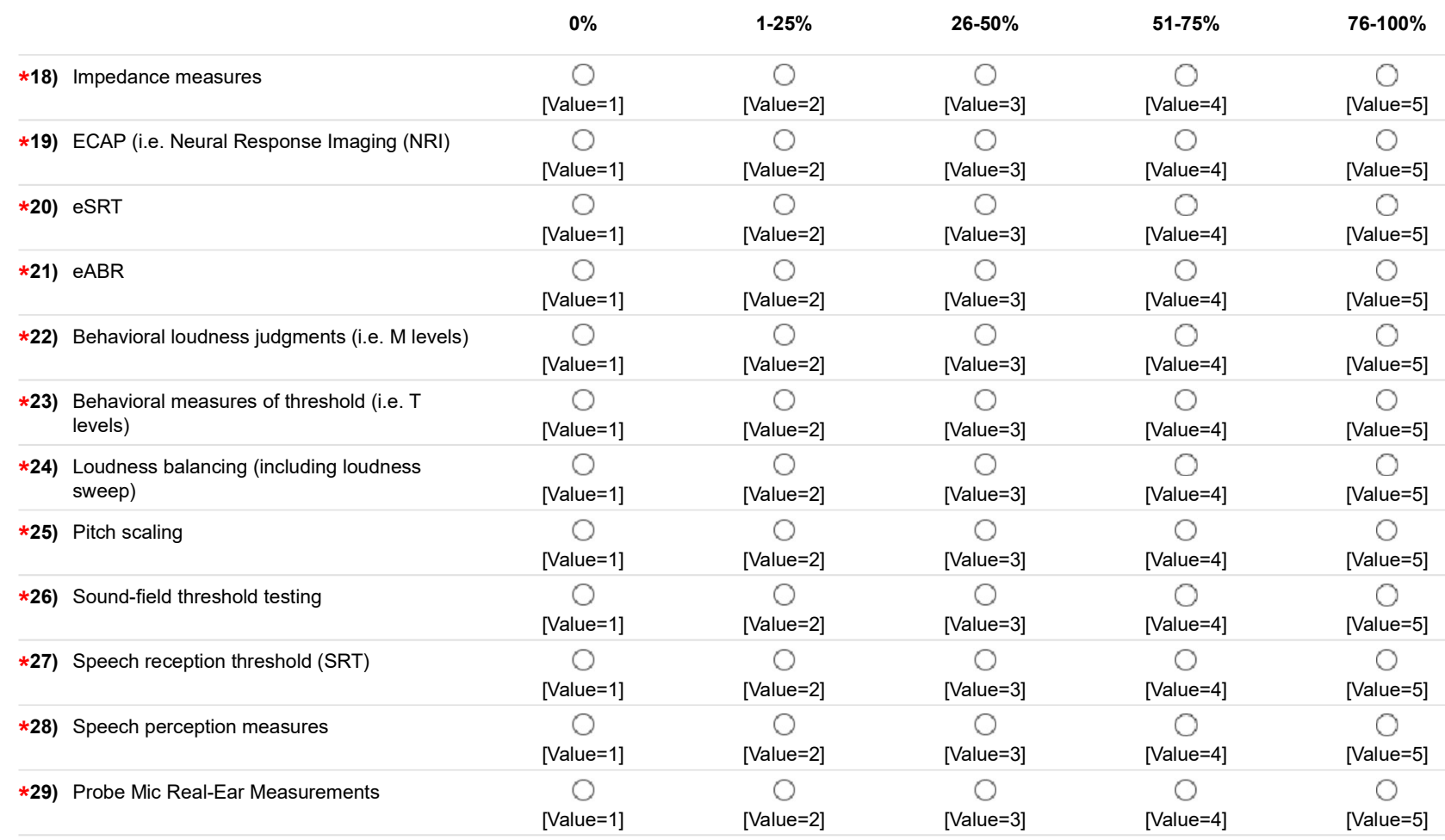

*30) In a typical programming appointment within the first year of the child having the device, on how many channels do you measure $T$ levels for a child with an $A B$ device? (If the number of channels on which you measure $T$ levels changes based on the child's age, please indicate this.)

*31) In a typical programming appointment within the first year of the child having the device, on how many channels do you measure $C / M$ levels for a child with an $A B$ device? (If the number of channels on which you measure C/M levels changes based on the child's age, please indicate this.) 


\section{Supplemental Appendix S1}

b. rarely [Value=2]

c. never [Value=3]

Question Logic

If [a. yes- often] is selected, then skip to question [No logic applied]

If [b. rarely] is selected, then skip to question [No logic applied]

If [c. never] is selected, then skip to question [\#47]

With what percentage of your pediatric patients that use Cochlear devices do you use each of the following approaches with:

*33) Impedance measures

*34) ECAP (i.e. Neural Response Telemetry (NRT)

*35) eSRT

*36) eABR

*37) Behavioral loudness judgments (i.e. C levels)

*38) Behavioral measures of threshold (i.e. T levels)

*39) Loudness balancing (including loudness sweep)

*40) Pitch scaling

*41) Sound-field threshold testing

*42) Speech reception threshold (SRT)

*43) Speech perception measures

*44) Probe Mic Real-Ear Measurements
$0 \%$

$1-25 \%$

[Value=1]

0

[Value=1]

$\bigcirc$

[Value $=1$ ]

[Value=1]

O

[Value=1]

[Value=1]

$\bigcirc$

[Value=1]

[Value=1]

$\bigcirc$

[Value=1]

[Value=1]

$\bigcirc$

[Value=1]

\section{O}

[Value=2]<smiles>COCCO</smiles>

[Value=2]

[Value=2]

O

[Value=2]

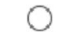

[Value=2]

$\bigcirc$

[Value=2]

O

[Value=2]

$\bigcirc$

[Value=2]

$\bigcirc$

[Value=2]

$\bigcirc$

[Value=2]

$\bigcirc$

[Value=2]

0

[Value=2]
$26-50 \%$

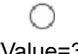

[Value=3]

[Value=3]

$\bigcirc$

[Value=3]

[Value=3]

Value $=3$

[Value=3]

[Value=3]

Value $=3$

[Value=3]

[Value=3]

$\underset{\text { Value }=3]}{0}$

$\bigcirc$

[Value=3]

$\underset{\text { [Value=3] }}{\bigcirc}$

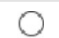

[Value=3]
$51-75 \%$

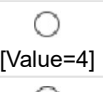

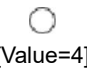

Value=4]

0

[Value=4]

$\bigcirc$

Value $=4$

[Value=4]

$\bigcirc$

O

[Value=4]

$\bigcirc$

$\mathrm{O}$

[Value=4]

${ }_{\text {Value=4] }}^{\bigcirc}$

0

[Value=4]

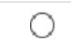

[Value=5]

0

[Value=5]

[Value=5]

0

[Value=5]

0

[Value=5]

[Value $=5$ ]

0

[Value=5]

0

[Value $=5$ ]

0

[Value=5]

0

[Value $=5$ ]

$\bigcirc$

[Value $=5$ ]

[Value=5]

*45) In a typical programming appointment within the first year of the child having the device, on how many channels do you measure T levels for a child with a Cochlear device? (If the number of channels on which you measure T levels changes based on the child's age, please indicate this.)

*46) In a typical programming appointment within the first year of the child having the device, on how many channels do you measure C/M levels for a child with a Cochlear device? (If the number of channels on which you measure C/M levels changes based on the child's age, please indicate this.)

*47) Do you work with MED-EL devices?
a. yes- often [Value=1]
b. rarely [Value=2]
c. never [Value=3]

Question Logic

If [a. yes- often] is selected, then skip to question [No logic applied]

If [b. rarely] is selected, then skip to question [No logic applied]

If [c. never] is selected, then skip to question [after \#62, Matrix Text] (See "Edit Logic" for details)

Page Break

With what percentage of your pediatric patients that use MED-EL devices do you use each of the following approaches with: 


\section{Supplemental Appendix S1}

*48) Impedance measures

[Value=1]

$\bigcirc$

Value $=3$

[Value $=4$ ]

[Value=5]

*49) ECAP (i.e. Neural Response Telemetry (NRT)

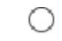

[Value=1]

0

$\mathrm{O}$

[Value=2]

[Value=3]

*50) $\mathrm{eSRT}$

O

[Value=1]

[Value $=2$ ]

$\mathrm{C}$

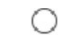

[Value=1]

0

*51) eABR

O

*52) Behavioral loudness judgments (i.e. C levels)

*53) Behavioral measures of threshold (i.e. $T$ levels)

[Value=1]

[Value=2]

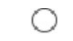

[Value=1]

[Value=2]

$=2]$

*54) Loudness balancing (including loudness sweep)

0

[Value=1]

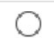

[Value=1]

0

[Value=1]

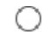

[Value=1]

O

[Value=1]

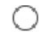

[Value=1]
0

[Value=2]

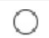

[Value=2]

$\bigcirc$

[Value=2]

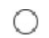

[Value=2]

O

[Value=2]

○

[Value=2]
[Value=3]

0

[Value=3]

0

[Value=3]

O

[Value=3]

O

[Value=3]

(

[Value=3]

0

[Value=3]

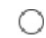

[Value=3]

Q

[Value=3]

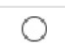

[Value=3]
0

[Value=4]

Value $=4$

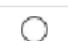

[Value=4]

Value $=4$

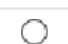

[Value=4]

0

[Value=4]

0

[Value=4]

Value $=4$

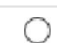

[Value=4]

Value $=4$

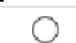

[Value=4]
0

[Value=5]

0

[Value=5]

0

[Value=5]

0

[Value=5]

0

[Value=5]

O

[Value=5]

0

[Value=5]

O

[Value=5]

0

[Value=5]

( )

[Value=5]

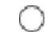

[Value=5]

*60) In a typical programming appointment within the first year of the child having the device, on how many channels do you measure T levels for a child with a MED-EL device? (If the number of channels on which you measure T levels changes based on the child's age, please indicate this.)

*61) In a typical programming appointment within the first year of the child having the device, on how many channels do you measure C/M levels for a child with a MED-EL device? (If the number of channels on which you measure C/M levels changes based on the child's age, please indicate this.)

These questions apply to all of your pediatric cochlear implant recipients.

*62) What is your typical follow-up care schedule for pediatric $\mathrm{Cl}$ recipients for the first two years post-implantation? Please describe using a list format. Example:

1 day post initial activation (IA)

1 week post IA

1 month post IA

etc. 


\section{Supplemental Appendix S1}

$\begin{array}{llclll}\text { Appt } & \text { Activatio post IA first wk month months months months year } \\ \mathbf{n}(\text { IA) } & & \text { post IA post IA post IA post IA post IA post IA }\end{array}$

*63) Impedance measures

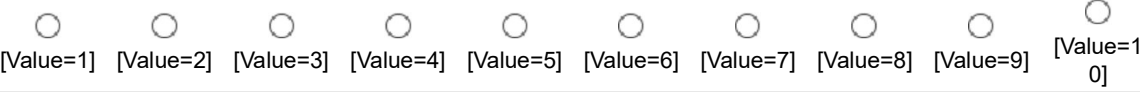

*64) ECAP (i.e. NRT, NRI, ART)

$\left[\right.$ [Value=1] [Value=2] [Value=3] [Value=4] [Value=5] [Value=6] [Value=7] [Value=8] [Value=9] $\begin{array}{c}\text { [Value=1 } \\ 0]\end{array}$

*65) $\quad$ eSRT

$\begin{array}{llllllllll}0 & 0 & 0 & 0 & 0 & 0 & 0 & 0 & 0\end{array}$ [Value=1] [Value=2] [Value=3] [Value=4] [Value=5] [Value=6] [Value=7] [Value=8] [Value=9] rValue

*66) $e A B R$

Value=1] [Value=2] [Value=3] [Value=4] [Value=5] [Value=6] [Value=7] [Value=8] [Value=9] [Value=1

*67) Behavioral loudness judgments (i.e. C/M levels)

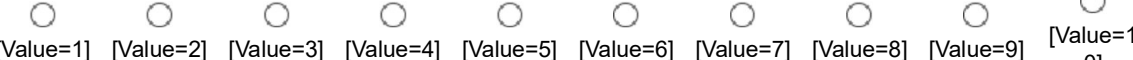

*68) Behavioral measures of threshold (i.e. T levels)

[Value=1] [Value=2] [Value=3] [Value=4] [Value=5] [Value=6] [Value=7] [Value=8] [Value=9] [Value=1

*69) Loudness balancing (including loudness sweep)

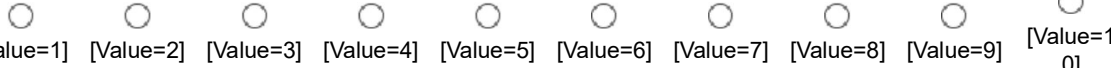

*70) Pitch scaling

O $0 \begin{array}{llllllll}0 & 0 & 0 & 0 & 0 & 0 & 0 & 0\end{array}$ [Value=1] [Value=2] [Value=3] [Value=4] [Value=5] [Value=6] [Value=7] [Value=8] [Value=9] $\stackrel{\text { Value }=1}{0}$

*71) Sound-field threshold testing

$\begin{array}{lllllllllll}0 & 0 & 0 & 0 & 0 & 0 & 0 & 0 & 0 & 0\end{array}$ [Value=1] [Value=2] [Value=3] [Value=4] [Value=5] [Value=6] [Value=7] [Value=8] [Value=9] $\begin{gathered}\text { [Value }=1 \\ 0\end{gathered}$

*72) Speech reception threshold (SRT)

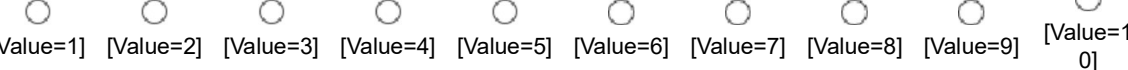

*73) Speech perception measures

Value=1] [Value=2] [Value=3] [Value=4] [Value=5] [Value=6] [Value=7] [Value=8] [Value=9] $\begin{gathered}{[\text { Value }=1} \\ 0\end{gathered}$

*74) Probe Mic Real-Ear Measurements

$\begin{array}{lllllllllllll} & 0 & 0 & 0 & 0 & 0 & 0 & 0 & 0 & 0\end{array}$ [Value=1] [Value=2] [Value=3] [Value=4] [Value=5] [Value=6] [Value=7] [Value=8] [Value=9] [Value=1

Indicate which assessments you use with the following age ranges, assuming a typically developing child. If you rarely use a certain measure or do not use it at all, simply select "I do not use this measure."

\begin{tabular}{|c|c|c|c|c|c|c|}
\hline & & $<2.9$ yrs & 3-5 yrs & $5-10$ yrs & $>10 \mathrm{yrs}$ & $\begin{array}{l}\text { I do not use this } \\
\text { measure }\end{array}$ \\
\hline$* 75)$ & IT-MAIS & $\begin{array}{c}\bigcirc \\
\text { [Value }=1]\end{array}$ & $\begin{array}{c}\bigcirc \\
\text { [Value }=2]\end{array}$ & $\begin{array}{c}\bigcirc \\
\text { [Value=3] }\end{array}$ & $\underset{\text { [Value }=4]}{0}$ & $\begin{array}{c}0 \\
\text { [Value }=5]\end{array}$ \\
\hline *76) & MAIS & $\begin{array}{c}\bigcirc \\
\text { [Value }=1]\end{array}$ & $\begin{array}{c}\bigcirc \\
\text { [Value }=2]\end{array}$ & $\stackrel{\bigcirc}{\text { [Value=3] }}$ & $\begin{array}{c}\bigcirc \\
\text { [Value }=4]\end{array}$ & $\begin{array}{c}\bigcirc \\
\text { [Value }=5]\end{array}$ \\
\hline *77) & ESP & $\begin{array}{c}\bigcirc \\
\text { [Value=1] }\end{array}$ & $\begin{array}{c}\bigcirc \\
\text { [Value }=2]\end{array}$ & $\begin{array}{c}\bigcirc \\
\text { [Value=3] }\end{array}$ & $\mathrm{O}_{\text {[Value }=4]}$ & $\begin{array}{c}0 \\
\text { [Value }=5]\end{array}$ \\
\hline *78) & PSI & $\begin{array}{c}\bigcirc \\
\text { [Value=1] }\end{array}$ & $\stackrel{\bigcirc}{\text { [Value=2] }}$ & $\stackrel{\bigcirc}{\text { [Value=3] }}$ & $\stackrel{\bigcirc}{\text { [Value }=4]}$ & $\begin{array}{c}\bigcirc \\
\text { [Value }=5]\end{array}$ \\
\hline$* 79)$ & WIPI & $\begin{array}{c}\bigcirc \\
{[\text { Value }=1]}\end{array}$ & $\begin{array}{c}\bigcirc \\
\text { [Value=2] }\end{array}$ & $\begin{array}{c}\bigcirc \\
\text { [Value }=3]\end{array}$ & $\underset{[\text { Value }=4]}{O}$ & $\underset{[\text { Value }=5]}{O}$ \\
\hline$* 80$ ) & NU-CHIPS & $\begin{array}{c}\bigcirc \\
\text { [Value }=1]\end{array}$ & $\begin{array}{c}\bigcirc \\
\text { [Value }=2]\end{array}$ & $\begin{array}{c}\bigcirc \\
\text { [Value=3] }\end{array}$ & $\begin{array}{c}\bigcirc \\
\text { [Value }=4]\end{array}$ & $\begin{array}{c}\bigcirc \\
\text { [Value=5] }\end{array}$ \\
\hline$* 81)$ & PBK-50 & $\begin{array}{c}\bigcirc \\
\text { [Value }=1]\end{array}$ & $\begin{array}{c}\bigcirc \\
\text { [Value=2] }\end{array}$ & $\begin{array}{c}\bigcirc \\
\text { [Value=3] }\end{array}$ & $\mathrm{O}_{\text {[Value }=4]}$ & $\begin{array}{c}0 \\
\text { [Value }=5]\end{array}$ \\
\hline$* 82)$ & MLNT & $\underset{[\text { Value }=1]}{\bigcirc}$ & $\begin{array}{c}\bigcirc \\
\text { [Value=2] }\end{array}$ & $\underset{\text { [Value=3] }}{\bigcirc}$ & $\underset{[\text { Value }=4]}{\bigcirc}$ & $\underset{[\text { Value=5] }}{\bigcirc}$ \\
\hline$* 83)$ & LNT & $\begin{array}{c}\bigcirc \\
\text { [Value }=1]\end{array}$ & $\begin{array}{c}\bigcirc \\
\text { [Value=2] }\end{array}$ & $\underset{\text { [Value=3] }}{\bigcirc}$ & $\begin{array}{c}\mathrm{O} \\
\text { [Value }=4]\end{array}$ & $\begin{array}{c}\mathrm{O} \\
\text { [Value=5] }\end{array}$ \\
\hline$* 84)$ & CID- sentences & $\begin{array}{c}\bigcirc \\
\text { [Value }=1]\end{array}$ & $\begin{array}{c}\bigcirc \\
\text { [Value=2] }\end{array}$ & $\stackrel{\bigcirc}{\text { [Value=3] }}$ & $\begin{array}{c}\bigcirc \\
\text { [Value }=4]\end{array}$ & $\begin{array}{c}\bigcirc \\
\text { [Value }=5]\end{array}$ \\
\hline$* 85)$ & HINT-C & $\begin{array}{c}\bigcirc \\
\text { [Value=1] }\end{array}$ & $\begin{array}{c}\bigcirc \\
\text { [Value=2] }\end{array}$ & $\begin{array}{c}\bigcirc \\
\text { [Value=3] }\end{array}$ & $\begin{array}{c}\bigcirc \\
\text { [Value }=4]\end{array}$ & $\begin{array}{c}0 \\
\text { [Value }=5]\end{array}$ \\
\hline$* 86)$ & BKB-SIN & $\underset{\text { [Value }=1]}{\bigcirc}$ & $\underset{\text { [Value=2] }}{\bigcirc}$ & $\underset{\text { [Value=3] }}{\bigcirc}$ & $\begin{array}{c}\bigcirc \\
\text { [Value }=4]\end{array}$ & $\begin{array}{c}\bigcirc \\
\text { [Value }=5]\end{array}$ \\
\hline
\end{tabular}




\title{
Supplemental Appendix S1
}

*87) Pediatric AZ Bio Sentences

*88) CNC words

[Value=1]

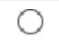

*89) HINT

[Value $=1$ ]

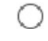

[Value=1]

*90) AZ Bio Sentences

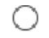

[Value $=1$ ]
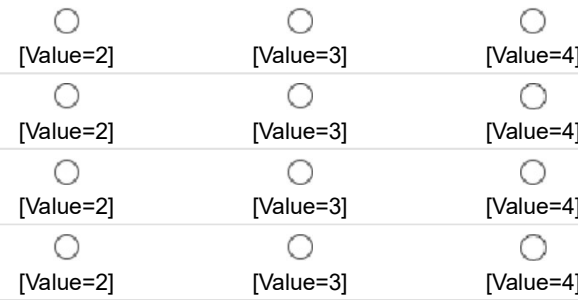

[Value=4]
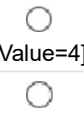

[Value=4]

$\bigcirc$

[Value=5]

0

[Value=5]

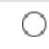

[Value=5]

0

[Value=5]

*91) If you use any assessment measures with your pediatric $\mathrm{Cl}$ patients that are not listed in the above question, please list them here. If you do not use any others, please type N/A.

1000 characters remaining)

\section{INVESTIGATION OF CURRENT NATIONWIDE COCHLEAR IMPLANT CLINICAL PRACTICE PATTERNS}

\author{
Thank you for completing \\ this survey, your input is very \\ valuable! All responses will be kept \\ confidential and will be \\ unidentifiable.
}

For maximum confidentiality, please close this window. 